\title{
$\mathrm{PH} 105$
}

Jiménez-Esquinas, G.

\section{Del Paisaje al cuerpo. La patrimonialización de la Costa da Morte desde la antropología feminista}

Bilbao: Universidad del País Vasco, 2021

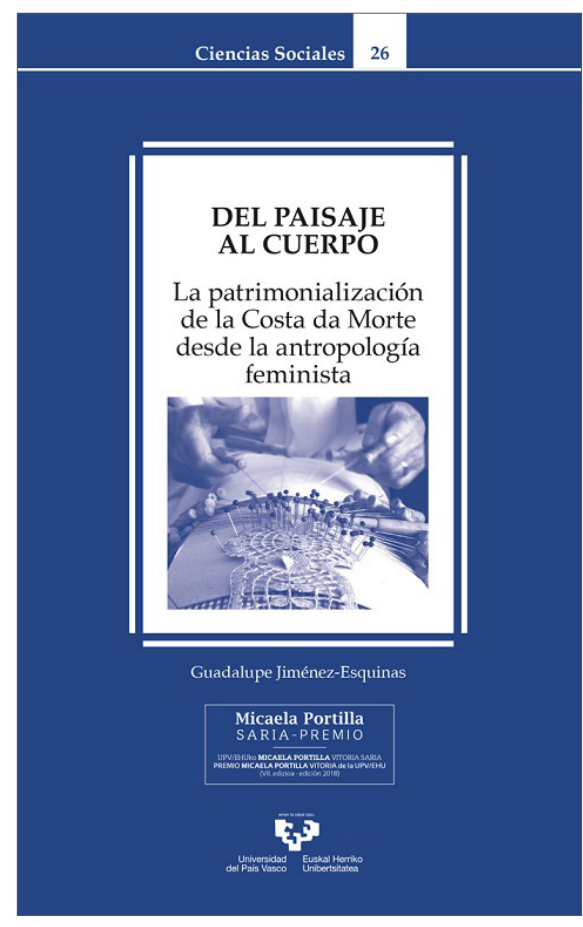

Este libro tiene su origen en un trabajo riguroso de investigación de tesis doctoral de carácter etnográfico. Su mirada feminista constituye una aportación relevante al campo de los estudios críticos sobre el patrimonio desde un punto de vista teórico y etnográfico. Como señala su autora, en este trabajo se privilegia "un proceso de patrimonialización que no afecta a un gran monumento, ni ha sido declarado por las instituciones autonómicas o internacionales, ni hay un amplio corpus de conocimiento sobre el mismo, sino que puede considerarse que es un patrimonio menor, no hegemónico, relacionado con una práctica laboral realizada por mujeres y en una zona periférica (p. 382)". Desde esta perspectiva la autora llevará a cabo una crítica a las políticas androcéntricas de patrimonialización y turistificación, en tanto apropiaciones del trabajo artesanal y, en particular, de los productos textiles que realizan las mujeres. Guadalupe Jiménez-Esquinas nos lleva con su investigación a la Costa da Morte (Galicia) para introducirnos y comprender el trabajo de las palilleiras que realizan el famoso encaje de Camariñas, desplazando su mirada del objeto (encaixe) a los contextos, acciones y vivencias de las artesanas, interrogándonos sobre el mismo hecho de preservar ¿para qué?, pero sobre todo ¿para quiénes? y ¿con quiénes?

Tras la introducción y un primer capítulo de descripción de la metodología que guía la investigación, la autora nos presenta en el capítulo segundo su propuesta teórica. A partir de aquí, nos sitúa en su contexto etnográfico, la Costa da Morte, y nos muestra cómo han sido representados los cuerpos de las mujeres, tanto desde miradas coloniales como nacionalistas, para adentrarse en la industria del encaje, objeto de las políticas patrimoniales que analiza.

En el capítulo quinto, a través de un recorrido histórico, nos vislumbra que el encaje, a pesar de haber sido una industria potente en la región, se ha sostenido bajo relaciones de explotación y precarización del trabajo de las palilleiras. Paradójicamente son estas mismas condiciones las que han permitido que siga vivo y sea objeto de patrimonialización, reproduciendo en parte, significados de una ruralidad exotizada.

Dedica el capítulo seis a las políticas de homogeneización cultural del franquismo y el fraguismo, en el marco de las cuales los artefactos textiles harán parte de la construcción de la "mujer ama de casa", contribuyendo a invisibilizar los trabajos de las mujeres, así como las condiciones de producción. Los 
dispositivos biopolíticos del franquismo al tiempo que circunscriben al hogar los trabajos de las palilleiras, exaltan como nuevo marcador identitario una figura folclorizada y despolitizada.

En los siguientes capítulos se adentra en el panorama actual del encaje de Camariñas, destacando que sigue manteniéndose desde condiciones de informalidad, feminización y precarización. El encaje constituye un oficio que se realiza por necesidades económicas y no por ocio y que, a pesar de los intentos de profesionalización, su aprendizaje sigue realizándose mediante su transmisión de generación en generación en el marco de relaciones informales entre mujeres.

Con su trabajo Jiménez-Esquinas nos muestra a las palilleiras como sujetas activas en relación con los procesos patrimoniales que les afectan y hace que nos interroguemos sobre el sentido que tiene preservar el encaje, en este caso, pero también cualquier otro artefacto, cuando se priman las representaciones, la celebración y exhibición y se obvian las condiciones de producción, y se despoja a las mujeres de sus saberes. Como afirma en su trabajo "cualquier proceso de patrimonialización que no garantice una retribución o unas condiciones de producción dignas resulta sumamente injusto, pues produce unas condiciones de violencia simbólica y estructural (p. 389)".

Samuel Rubio Coronado, Carmen Gregorio Gil | Grupo de investigación Otras.

Perspectivas Feministas en investigación social, U. de Granada

URL de la contribución <www.iaph.es/revistaph/index.php/revistaph/article/view/5079> 